\section{DIGITAL COMMONS \\ @ UNIVERSITY OF SOUTH FLORIDA}

\section{ब(96R)}

Journal of

Global Education and Research

June 2019

\title{
Rethinking the meaning of study abroad programs: The learning experiences of two female Gambian students in Taiwan
}

\author{
Virginie Marc \\ National Taiwan Normal University, marcvirginie12@gmail.com
}

Follow this and additional works at: https://digitalcommons.usf.edu/jger

Part of the Adult and Continuing Education Commons, Curriculum and Instruction Commons, Higher Education Commons, and the International and Comparative Education Commons

This Refereed Article is brought to you for free and open access by the M3 Center at the University of South Florida Sarasota-Manatee at Digital Commons @ University of South Florida. It has been accepted for inclusion in Journal of Global Education and Research by an authorized editor of Digital Commons @ University of South Florida. For more information, please contact digitalcommons@usf.edu.

\section{Recommended Citation}

Marc, V. (2019). Rethinking the meaning of study abroad programs: The learning experiences of two female Gambian students in Taiwan. Journal of Global Education and Research, 3(1), 37-57.

https://www.doi.org/10.5038/2577-509X.3.1.1028

Corresponding Author

Virginie Marc, 8F, No.6, ZhongPu 6th Street, Taoyuan District, Taoyuan City, Taiwan ROC

Revisions

Submission date: Aug. 14, 2018; 1st Revision: Dec. 1, 2018; 2nd Revision: Feb. 5, 2019; 3rd Revision: Jun. 13, 2019;

Acceptance: Jun. 20, 2019 


\title{
Rethinking the Meaning of Study Abroad Programs: The Learning Experiences of Two Female Gambian Students in Taiwan
}

\author{
Virginie Marc \\ College of Education \\ National Taiwan Normal University, Taiwan \\ marcvirginie12@gmail.com
}

\begin{abstract}
This paper is an ethnographic effort which examines the effects of oppression and social inequality on the learning experiences of foreign students in Taiwan, focusing on two female Gambian students. The theoretical frameworks utilized to interpret the learning experiences of these foreign students in Taiwan include Freire's critical pedagogy, critical travel pedagogy, global citizenship, and experiential learning. Unstructured interviews and observations were selected for data collection, and the findings suggest these international students used their learning experiences as a tool to transform their lives and their perspectives on the future of Gambian society. The findings also show these study abroad experiences raised the students' consciousness of the social, political, and economic disparities between the two nations and led them to act against oppression while helping them develop their critical thinking skills and place a high value on intercultural understanding.
\end{abstract}

Keywords: experiential learning, Freirean perspective, women's emancipation, global citizenship

\section{Introduction}

As we live in an interconnected world today, studying abroad effectively educates individuals in several ways: developing new perspectives on academic subjects, experiencing real-world issues, learning foreign languages, experiencing personal growth and cultural understanding, developing valuable career skills (Study Abroad, n. d.), and, last and foremost, awakening personal consciousness of one's world (Freire, 2000a). Studying abroad is not only about preparing oneself for academic work; instead, its prime purpose is to experience new social and cultural lifestyles (Vijeyavelan, 2012). This experience can facilitate the development of life-changing skills which promote personal, intercultural, and professional development. Studying abroad is important for students to get a globalized education (Steves, 2012), which enables them to thrive. While studying abroad, students can become more aware of the challenges of their own nations and cultures and develop an understanding of the role and importance of tolerance and intercultural communication. Students who go abroad are expected to acquire not only intercultural communication skills and national awareness, but also critical skills, global awareness (Burn, 1980); efficiency in their field of study; political, historical, and geographical knowledge of other cultures; and most importantly, an understanding of the contemporary international context, its problems, and potential solutions (Kauffman, Martin, Weaver, \& Weaver, 1992). 
It is important to clarify what studying abroad entailed in the case of Gambian students studying in Taiwan. Bochner, Furnham, and Ward (2001) proposed the terms intercultural contact, sojourners, and host cultures, among many more. These three terms were selected for their relevance to this study. Put in this context, the two Gambian students were sojourners (international students expecting to return home after completing their studies) in Taiwan (the host culture), where they met many people and learned many things (intercultural contact).

This article explored the meaning of a study abroad program for two female Gambian students in Taiwan. The exploration process included reviewing the literature, introducing the research approaches applied in this study, and then discussing the two participants' learning experiences in Gambia and their emerging learning experiences in Taiwan. This research explored these cases of studying abroad using Freire's (2000a) theory, especially his dialogical theory, which can be described as a process of learning and knowing. Freire's (2000a) political philosophy was used to interpret the two Gambian students' experiences. The study's aim was to uncover the critical consciousness of the need of the current and aspiring students to enter into dialogue with local people and other foreigners - where they studied, as a process of learning and knowing.

\section{Related Studies}

Gemignani (2009) completed research, which focused on gaining an understanding of culture learning in studies abroad through the perceptions of international undergraduate students. Findings of this study revealed more about understanding the meaning of the study abroad experience for students than about understanding culture learning. Additionally, the meaning of study abroad involves (a) what students learn, (b) incorporation of the learning experience into personal life, and (c) connection with people. Five years later, Rodriguez (2014) completed a doctoral dissertation which investigated the perceived impact of graduate counseling students' study abroad activities. Three themes emanated from the findings of this study: (a) adaptability and personal growth, (b) becoming aware of diversity, and (b) group process. Both studies found students had gone through cultural/social adjustment before meaningful learning experiences took place. This means students studying abroad must be open, ready to get out of their comfort zones and manage their frustrations. One of the frustrations the counseling students faced was the language barrier.

Chou (2013) completed research which explored and identified international students' academic and social learning experiences in Taiwanese higher education institutions. Chou surveyed 106 international students and interviewed 21 faculty members in Taiwan. Chou's findings revealed these international students experienced a variety of learning and social barriers in Taiwanese universities. These barriers were: (a) class material comprehension; (b) communication with professors, staff members, and peers; and (c) understanding Taiwanese culture and finding supportive services on campus. Chou (2013) also listed several factors which affected foreign students' learning experiences, namely: (a) gender, (b) educational level, (c) school, (d) major, (e) nationality, and (f) study length.

Several studies-before and after these three studies cited in this review-reported limited language skills as a potential barrier to learning. Chou's (2013) findings identified language clearly while explaining international students' frustrations related to available English resources, and involvement in students' programs and clubs. Limited language skills can obtrude into peer interactions. For decades, many higher education institutions have supported peer interaction to address several increasing diversities. These institutions applied the Jigsaw technique (which 
involves dividing students into groups for class assignments) in order to decrease racial issues among students, increase learning and change students' attitudes about their scholarly abilities (Crone \& Portillo, 2013). This technique may not be completely successful in Taiwanese higher education because, as exemplified in Chou's (2013) findings, some local students are shy to converse with foreign students, especially in English. Study abroad programs hope students benefit from peer interactions, but it does not occur naturally as many local and foreign students feel more comfortable interacting with their own country mates. Indeed, Fernandez (2006) reported in her study that international students felt pressured to interact with only people of their own cultural background. However, many institutions and even peers use online interaction to cover the gaps of face-to-face interaction. Results of a study conducted by Yang and Chang (2012) indicated online peer interaction has a positive effect on student academic achievements.

Research on study abroad analyzes the experiences of foreign students throughout the study abroad program/curriculum, and how these students adjust to fit the new environment and culture. Little research reported upon curriculum messages sent by study abroad programs. These messages can be seen as a hidden curriculum. The simplest definition of hidden curriculum is the meaningful things students learned outside their formal learning. Vallance (1974) labeled it as social control function of schooling, whose functions are identified as the inculcation of values, political socialization, training in obedience and docility, and the perception of traditional class structure. Vallance's description of hidden curriculum exposed the discrepancies in the formal curriculum in American schooling. Killick (2016) argues higher education institutions bring the exposed and interrogated hidden curriculum into alignment with the formal curriculum (i.e., when it comes to curricula change). Killick's view on the curriculum messages is they can only conflict with the intended curriculum. For instance, when foreign students are affected by group inequalities, seeing the other as competitor, the privileging of native speaker language competencies, and holding divergent task orientation and goals, there is a lack of formal recognition of the value of positive intercultural per se. Killick (2016) suggests these factors can contribute to students' transformative learning as competent, who learns from multi-perspectives and who values viewing the world from multiple worldviews.

The adoption of Chou (2013) and all the studies cited above in this review are necessary to the present study in that it assesses one of Taiwan's most popular trend: presence of international students in Taiwanese higher education institutions. This study explored the learning experiences of two female Gambian students in Taiwan, but most importantly, it also revealed the meaning of study abroad from women's perspectives. This effort was a milestone because of its ability to echo African women pursuing higher education in Taiwan. The challenges international students face are not necessarily new; however, these challenges can overwhelm them during the study abroad experience.

\section{Making International Students Into More Engaged Global Citizens}

To understand how students learn from their experiences abroad and what happens during this learning process, it is necessary to examine critical travel pedagogy. This pedagogy encourages people to participate in and respect each other's cultures and to take the learning process beyond superficial differences and stereotypes (Hanvey, 1979) as students learn new languages, gain cross-cultural communication skills, and develop a sense of independence. Critical travel pedagogy, thus, has the potential to help students develop critical thinking skills and place high value on subjective experiences in intercultural understanding. For the purpose of this article, "critical travel pedagogy focuses explicitly on raising critical consciousness about the issues of 
oppression and social injustice" (Johnstone, 2011, para. 2). Johnstone (2011) introduced this theoretical framework to fill the gap of literature between education and the intersection of oppression, globalization, and travel. Johnstone's (2011) theoretical framework stresses experiences formed based on a variety of theories including anti-oppressive education (Kumashiro, 2000), global consciousness (Mansilla \& Gardner, 2007), critical theory (Freire, 2000a), multicultural education (Nieto, 2004), and teaching compassion (Carson \& Johnston, 2001). Johnstone (2014) finalized the development of critical travel pedagogy by adding experiential learning theory, thus, basing his theory which on six fundamental theories. Johnstone's (2014) contribution is a unique pedagogical approach which study abroad programs can use to developing students' critical consciousness. Johnstone's (2014) argued in favor of his conceptualization by stating this pedagogical approach should inspire participants to change themselves and society.

Many scholars agree studying abroad has some benefits: international students are likely to learn to be more independent and self-reliant, and acquire survival skills to cope with new environments (Kauffman et al., 1992). They often undergo personal growth - especially in communication, other languages, and a global worldview (Burn, 1980; Kauffman et al., 1992; Ostrand, 1986). However, Kauffman et al. (1992) firmly believe studying abroad by itself does not necessarily lead to the development of global citizenship or experiential education because not all students studying abroad open-mindedly embrace the local culture or appreciate the lifestyles of the host country.

In reviewing global citizenship theory and the challenge to define it from various perspectives, the following sources are relevant: an economic model (Burbules \& Torres, 2000; Chomsky, 1998 Stiglitz, 2002); global, political, and economic changes (Ong, 2004); social (Castells, 1997; Touraine, 1988); moral responsibility (Heater, 2002); and supranational political authority and political action beyond the nation-state (Heater, 2002). To guide this study, I adopted Ong's (2004) definition focused on global, political, and economic changes. Acquired knowledge, attitudes, and skills will empower international students to function in global society and fully integrate into the global world as active, responsible citizens to transform their societies (Szelenyi \& Rhoads, 2007; Banks, 2008).

However, not everyone has access to global citizenship, not even in its simplest form in Kant's idea that human beings belong to a single moral community (Peters, Blee, \& Britton, 2008). A world ethic, however, is ineffective because moral values vary among nation-states. International education, though, according to Ong (1999), provides a space for the proliferation of a flexible citizenship prototype of capitalist accumulation, travel, and persuasive transfer subjects to respond fluidly and opportunistically to changing political economic conditions (Szelenyi \& Rhoads, 2007).

In the theory of learning experience, Dewey (1997) identified two basic principles of experience: continuity and interaction. From his perspective, continuity is the concept every experience takes a person's past experiences and employs them in the present and the future. He also believed continuity is the constant effort to evaluate whether an experience is instructive or not.

Every experience is a moving force. Its value can be judged only on the grounds of what it moves forward and into.... The lack of mutual adaptation made the process of teaching and learning accidental. Those to whom the provided conditions were suitable managed to learn. Others got on as best they could. (Dewey, 1997, p. 18)

The factor of continuity is intertwined with interaction, or the interplay between individual background experiences, or the internal and objective conditions set up by the educator. The 
educator cannot control students' backgrounds or the past, only the objective conditions of the present. The variables which the students possess make each educational interaction different. Traditional education assumes that students meet certain internal and external conditions, and that they all interact with the material in the same way. However, "it is then the business of the education to see in what direction an experience is heading” (Dewey, 1997, p. 14).

A third critical element in experiential education is active reflection, which is critical for continuity. Stemming from this idea, according to Dewey (1933), reflection denotes examination of one's past experiences to apply knowledge for growth in new experiences. It is the key to providing continuity with subsequent interactions and students' construction of past knowledge and experiences. Experience is part of the living process; thus, it occurs continuously, and "we have an experience when the material experienced runs its course to fulfilment" (Dewey, 1934, $p$. 35). He explained this claim, adding:

A piece of work is finished in a way that is satisfactory; a problem receives its solution; a game is played through; a situation, whether that of eating a meal, playing a game of chess, carrying on a conversation, writing a book, or taking part in a political campaign, is so rounded out that its close is a communication and not a cessation. (Dewey, 1934, p. 35)

\section{Enabling Women's Emancipation Via Critical Thinking Skills}

Women's marginalization has been a major obstacle to the achievement of fair opportunities within many societies. Assertions that women are inferior to men by nature come from patriarchal systems maintaining the ideology that male authority and female subordination are naturally designed: a context which often disadvantages and oppresses women (Walby, 1986, 1990). Feminist theory has challenged the tradition of male supremacy by acknowledging biological gender differences and the lack of evidence for a natural patriarchal order and by promoting women's emancipation in society. Moreover, many researchers and philosophers (e.g., Astell and Springborg, 2002; Hobbes, 1998; Owen, 1999; Springborg, 2005; Wollstonecraft, 1988) have shown that rational thinking and empirical evidence can demonstrate the falsity of these assertions (of male supremacy) (Jonasdottir, 1994).

Furthermore, Freire (2000a) believed in human's potential to strive and advocate for a critical pedagogy that, in his view, leads to the creation of new forms of ethical and political communities. Critical consciousness or conscientizacao should be a product of literacy, which is - learning to perceive social, political, and economic contradictions, and to act against the oppressive elements of reality (Freire, 1970, 2000b). In Pedagogy of the Oppressed, Freire (2000a) explained the link between teaching and consciousness-raising as a teaching method for adults. Freire (2000a) not only helped peasants become literate by employing critical thinking skills, but also facilitated the development of a critical consciousness in them so through social action, they could change the social, political, and economic structures of their community together. Freire (2000a)'s perceptions of humankind and oppression aid in understanding methods of raising consciousness. According to Freire (2000a), there are two conceptions on humankind. One conceives of humans as objects: modifiable and adaptable. The second perceives humans as subjects: independent beings capable of transcending and re-creating the world. Freire (2000b) argued human beings are not simply submerged in the world and cannot be seen as objects; instead, humans are subjects in and with the world. Consciousness is determined by socio-economic and political contexts, and cultural conditioning through upbringing, education, and religion (Freire, 2000b). This is the context in which oppression dehumanizes people, so they follow the social guidelines prescribed by their 
oppressors (Freire, 2000a). The oppressed, thus, are adapted to a culture of myths, which makes them silent (Freire, 2000a); consequently, they need to liberate themselves from their suppressive reality.

Feminist theory claims, in most cultures, male-dominated society has oppressed and marginalized women (Jonasdottir, 1994). Chafetz $(1988,1997)$ described four criteria of feminist theory: (a) it should be centered on gender; (b) it views gender relations as characterized by problematic inequities, strains, and contradictions; (c) it does not view gender relations as immutable; and (d) it serves as an alternative tool to challenge, counteract, or change the status quo which disadvantages or devalues women. Flax (1983) viewed feminist theory as intimately related to action, providing a foundation for action and denying that theory can be neutral. Feminist theory has a steadfast mission to change oppressive social norms and connect abstract beliefs with concrete social issues to achieve political action, in particular, challenging misconceptions in traditional political theory whose assumptions about women hinder the full achievement of equality (Okin, 1979). I believe there must be a social and political commitment to do something about women's situation. Too often, little girls are repeating the social behaviors they have learned directly or indirectly from their families and/or communities. It is my stand that women's situation must be socially and politically handled. Historians have observed that the women's rights movement has changed traditional understandings of certain expectations of social institutions, such as marriage, education, property ownership, professional ambitions, and political involvements (Lemak \& Hopkins-Benton, 2017; Lindsey, 2015; Wyrod, 2008).

The feminist movement has been successful and extended beyond Europe and the United States to the situation of women in African countries. I, therefore, hope to draw readers' attention to the conscious awakened, especially regarding the situation of Gambian women as represented by the two female participants in this study. Researchers often use the terms feminist movement and women's emancipation interchangeably and define them as organized efforts by women to achieve legal and political equality (Evans, 1977; Offen, 1988). The term feminism is both controversial and broad, because it includes different views on women, motherhood, and men's engagement in the cause of women's emancipation (Offen, 1988).

\section{General Background of Learning Experiences in Gambia}

Gambian students face great educational challenges due to the high cost of tuition. Gambian government only provides five years of free education through elementary school. Consequently, many students withdraw from school early due to monetary difficulties, failure to pass standardized exams, and disillusionment about the value of education-given the lack of jobs in the nation (Access Gambia, 2013a). Historically, boys are more likely to finish school than girls due to religious beliefs and cultural traditions (Touray, 2006). However, due to foreign influence and feminist movements, more girls are enrolling into schools and are pursuing higher education today. As a huge progress on gender parity in enrollment under the initiative of National Education for All (EFA), Gambia National Commission for UNESCO has reported an increase in the number of girls who were enrolled in both basic and secondary education from 1999 to 2014. For instance, the review revealed a significant increase in the net enrolment ratio of Gambian girls-from 55.4 $\%$ in 1999 to $80.6 \%$ in 2014 (Republic of Gambia, 2015).

At the university or tertiary level, students face the same financial difficulties and only those who can afford the tuition fees attend these institutions. The University of Gambia, the nation's only university, has limited resources, such as slow Internet connection and some useful books - mostly 
donated by overseas universities, many of which are outdated (Access Gambia, 2013b). Consequently, Gambian students often seek opportunities to study abroad. The United Kingdom is the most preferred destination for overseas learning experience for Gambian students.

Taiwan provides scholarships as a government strategy to attract foreign students to its universities (Chou, Roberts, \& Ching, 2012), and among Taiwan's African allies, Gambia is the biggest beneficiary of the program due to the country's strong diplomatic relations (Jawneh, 2013). (Note: this study was already underway when Gambia broke off diplomatic relations with Taiwan in November 2013.) These good diplomatic relations can be understood as such: Gambia plays an active role in international affairs, especially West African and Islamic affairs (Bureau of African Affairs, 2013). Aware of the importance of education and occupational training, Taiwan is committed to strengthening its diplomatic allies' development of human resources through a winwin scenario: effective, specialized bilateral aid programs (Ministry of Foreign Affairs, Republic of China, Taiwan, 2012).

Two hundred Gambian students studied in Taiwan in 2011 (Jawneh, 2011). Gambian students receive four categories of scholarships from Taiwan: International Cooperation Development Fund (ICDF), Ministry of Foreign Affairs, Gambia-Taiwan Cooperation, and university scholarships. These students acquire skills in many fields including agriculture, petroleum, medicine, architecture, engineering, and human resources; they stay in Taiwan for two to five years to complete their studies, depending on their level (undergraduate or graduate). Many Gambian students with whom I am personally acquainted have assurances of jobs in Gambia or expect the government to provide employment for them as it plans to absorb them into the system.

\section{Oppression of Women in Gambia}

Oppression of women in Gambia manifests in various social, political, and economic forms, in particular, female genital mutilation (FGM). It is difficult to discuss the oppression of women in Gambia without also discussing FGM. The latter is a prevalent non-medical practice that jeopardizes the health, sexuality, and life of Gambian women. Gambian women who have undergone FGM are more vulnerable to bacterial vaginosis and herpes simplex 2. Gambian law does not protect girls from any form of FGM (clitoridectomy and/or excision), and the political will to stop it is weak in the face of the argument that the practice is an important cultural symbol (Touray, 2006).

Among other forms of repression, "girl children suffer early discrimination in terms of education and socialization/sexualization, while their mothers' sexual options are also circumscribed by the sex of their babies" (Touray, 2006, p. 78). Many girls withdraw from school due to early marriage, which is viewed as a highly honorable and dignified practice (Touray, 2006). The fear of unwanted pregnancy is also a frequent argument for early marriage in Gambia, although early male sexual indulgence is rarely questioned (Touray, 2006). Women's own views on their needs and rights are ignored as if they are unimportant.

\section{Researcher's Positionality}

Being an international student myself during the time of this study, researching the meaning of study abroad through the learning experiences of two Gambian students was a reflective endeavor. Thus, it made me an insider researcher. However, as a woman, I lack understanding of (a) what it is like to be a wife and mother who is from a patriarchal society, and (b) how such a woman 
Journal of Global Education and Research, Vol. 3, Iss. 1 [2019], Art. 4, pp. 37- 57

experiences her study abroad. The intention was to understand more about what such a woman experienced, what study abroad meant to her, and most importantly, how she describes her learning experiences.

Furthermore, concerning position as both a researcher and a friend am aware that although, on one hand, relationship with the participants can be seen as a cause for compromise on my professionalism and impartiality, on the other hand, it strengthens my research by providing access to more information and flexible interview times with the two participants. Therefore, these criteria allowed me to observe and communicate with the participants in a more frequent and effective manner.

However, as mentioned, it hinders my professionalism. For instance, even the invitation to the interviews was sent formally through emails. However, further explanations on the interviews used Facebook text messages. It also limited my research by making it difficult to ask pertinent and sensitive questions which the participants may not have been comfortable answering. These challenges were mitigated during the research process by reaffirming the purpose of the study and my role as researcher, and by double checking meanings with the participants. Considering the cultural, educational, and socioeconomic challenges in Gambia and the challenges facing these students while abroad in Taiwan; as well as the limitations of my positionality as an international student, a qualitative research study was conducted using the following research question: "to what extent do the learning experiences in Taiwan help these students contribute to the social transformation of the Republic of Gambia?" Additionally, the theoretical framework for this study involves four theories, enabling interpretation of the interview data collected. These theories include: Freire's (2000a, 2000b) critical pedagogy, critical travel pedagogy, global citizenship, and experiential learning.

\section{Methods}

\section{Research Design and Procedures}

Given the study's exploratory nature, the methods were based on interviews and observations. Unstructured interviews were conducted (i.e., audio recorded and transcribed) to explore the two international female students' learning experiences and to understand how these experiences transformed them. In some ways, the interviews were very similar to conversations (Burgess, 1984). Unstructured observations were also conducted (naturally and interruptedly) to determine how the two Gambian female students interacted and behaved in the environments. Accordingly, the interview questions focused on learning experiences, cultural differences, culture adjustment, consciousness awakening, and emancipation. Data were collected to understand the participants' experiences, avoiding the use of ordinal values (Nkwi, Nyamongo, \& Ryan, 2001). Furthermore, sources of data included official websites and reports, books, scientific journals, and conference articles.

The purpose of the paper is to examine the effects of oppression and social inequality with the intention to stimulate critical thinking among local and international students and faculty members in Taiwan. Here, critical thinking refers to the ability to offer evidence and reason for positions (i.e., judgement skills and application to problems and issues). International students refer to all students participating in education abroad. 


\section{Participants}

The research participants were two Gambian female students. They were selected due to their willingness to talk about their learning experiences and their awareness of the environment in which they lived. Both students were enrolled in a two-year master's program in one of Taiwan's elite universities during the 2012-2013 academic year. The master's study required the two women to leave their families entirely to come to Taiwan. These two women were relevant to the study's aims due to their experiences as mothers, employees, and Gambian foreign students.

Selection was undertaken informally after being aware of the participants' characteristics, and invitations to participate in the study were sent via email. There were three reasons for the sample size of two: (a) the study method was qualitative, so $n=2$ was appropriate; (b) the sample was convenient; and (c) the intent was to study women's experiences.

\section{Data Collection}

The study period consisted of seven months of observations and interviews from March to September 2013. There were five interviews and three observations over the course of this study. During that time, the participants were observed every day; so, it was difficult to pick one specific area to observe. They were observed mainly at the dormitory. The data collection was convenient because the study participants were my schoolmates and acquaintances. This strengthened the research by providing access to more information and allowing flexibility in scheduling the interviews. However, it limited the research by making it difficult to ask pertinent, sensitive questions the participants might not have been comfortable answering. Upon completing the data collection, it was necessary that the participants were given pseudonyms, thereby maintaining the anonymity and confidentiality of the study participants. Table1 below shows details on the schedule of interviews and observations conducted for this study.

Table 1. Schedule of the Interviews and Observations

\begin{tabular}{clllll}
\hline No. & \multicolumn{1}{c}{ Names } & \multicolumn{1}{c}{ Date } & \multicolumn{1}{c}{ Duration } & \multicolumn{1}{c}{ Topic/context } & \multicolumn{1}{c}{ Types } \\
\hline 1 & Sarah & 28-Mar-13 & $1: 12: 00 \mathrm{hrs}$. & Experiences/feelings & One-on-one interview \\
2 & Carol & 31-Mar-13 & $0: 53: 12 \mathrm{hrs}$. & Experiences/feelings & One-on-one interview \\
3 & Sarah/Carol & 04-Apr-13 & $9: 00: 00 \mathrm{hrs}$. & Irregular eating times & Observation \\
4 & Sarah/Carol & 16-Apr-13 & $0: 20: 09 \mathrm{hrs}$. & Cooking lunch & Observation \\
5 & Sarah & 21-Apr-13 & $0: 11: 43 \mathrm{hrs}$. & A typical day & One-on-one interview \\
6 & Carol & 21-Apr-13 & $0: 13: 20 \mathrm{hrs}$. & A typical day & One-on-one interview \\
7 & Sarah/Carol & 5-May-13 & $0: 15: 34 \mathrm{hrs.}$ & Statistics homework & Observation \\
8 & Sarah/Carol & 06-Jun-13 & $1: 30: 12 \mathrm{hrs}$. & Learning experiences & Group interview \\
\hline
\end{tabular}

In constructing the interview protocol, techniques outlined by Marshall and Rossman (2006) were relied upon, particularly his delineation of different types of qualitative questions: exploratory, explanatory, descriptive, and emancipatory questions. The interview questions were asked to access the participants' background knowledge of peer expectations and their family structure, values, conflict resolution, roles, history, and response to failure. The descriptive data helped me understand the sociocultural context which shaped the two students as human beings and gave me a broad idea of life in Gambia. For example, the participants were asked, "What was your childhood like? And how were families in general, and your family in particular structured in Gambia?" 
Exploratory questions were asked to understand the motives which brought these students to study in Taiwan and the relationship between Taiwan and Gambia (e.g., "How did you end up coming to study in Taiwan? What were the procedures?"). Emancipatory questions were also posed to identify the knowledge, experiences, and challenges facing these international students in both Taiwan and their home country: "Based on your feelings and experiences, what are the differences between life (including study) in Taiwan and life in Gambia? Please share these feelings and experiences based on the following social groups: family, peers, school, dormitory, and yourself."

This approach was relevant for this study because it allowed me to capture data which I would otherwise never find in literature reviews or documents. The validity of qualitative research can be biased by the lack of accurate information from the participants. Validity refers to the degree to which the research findings accurately reflect the real-world facts they purport to describe. A careful literature review and data review, verification, and interpretation with the two participants were undertaken to respond to this potential limitation.

\section{Data Analysis}

To analyze the interview data, simple qualitative techniques were used to facilitate the research findings. First, all the interview data was carefully transcribed and read. During this process, I compared them with my notes, and for clarification, I double checked with the participants. Second, I used coding categories based on the research framework. This type of coding involved a perspective held by subject that enabled me to make critical and objective deductions. Third, I interpreted the meaning of each response carefully according to the selected theories. At this point, I was able to write up the findings and draw conclusions.

\section{Discussion of the Findings}

The findings are presented according to the data analysis of the observations and interviews conducted for this study. Findings of the interviews also involve the following emergent themes: Emerging learning experiences in Taiwan, Ongoing learning, Adjusting behaviors to better fit social norms of the host culture, and Sarah and Carol's Impressions of Taiwan.

\section{Findings From Observations}

Findings from observations picture Sarah's and Carol's study abroad life experiences. First, their irregular eating schedule was observed from 12: $30 \sim 9: 30$ pm: breakfast was eaten around 1:00 $\mathrm{pm}$, lunch at 4:00 pm, and dinner was made at 9:00 pm. This habit was very common among the international students living in the dormitory, it is assumed that the two participants had followed the same pattern. The participants rushed to make lunch because they wanted to be on-time for the 2:00 pm class. Sarah emotionally said "you are wasting my time" to a classmate who wanted to warm up her meal on the unique electric stove on the floor, but which took longer. This scene shows how, after coming to Taiwan, they grew to appreciate the importance of home-made meals and being on-time for their classes. Another 15 minutes' observation was completed in the living room while the participants were trying to answer some statistics exercises relating to mean, median, and average. I stopped observing the scene until I was asked to help out with their homework. This last scene shows how they have tried to cope with the master program (i.e., the many assignments and the strict deadlines that come with them). They were proud to be Gambian because on some days, they were observed wearing their national clothes - shouting "this is Gambia". 


\section{Findings From Interviews}

Sarah and Carol, at 43 and 30 years old respectively, were both wives and mothers from big families from Gambia, a country dominated by a patriarchal family system. Sarah was from a family of 12, and Carol - from a family of 10. Most of their siblings were married and had children. The families lived with their parents, grandparents, and siblings in what they call compounds in Gambia. Their religion was Islam, but seldom did they wear a hijab or a burka (a hijab is a headscarf while a burka covers the entire body including the face), which is often an individual choice by Muslim women.

Prior to the master's degree, the two participants were working in Gambia. Sarah was a teacher at an elementary and a secondary (in her own words: Lower Basic School and Upper Basic School) and also an employee at a Gambian Women Bureau. She received both a primary teacher certificate as well as the highest teacher certificate. For her bachelor's, she majored in Development Studies and minored in Management. Carol was a Relationship Manager at a Standard Chartered which is a bank. She majored in English Language and minored in Political Science.

Sarah and Carol did not know one another prior to arriving in Taiwan. In her own words, Carol states: "We got to know each other after we got the scholarship and started to meet as a group. We didn't know each other prior to that."

Sarah and Carol believed that education helps women progress professionally. Despite the difficult responsibility of caring for their families while living abroad, they considered education to be their priority in life. Upon sharing her feelings and experiences during the interview, Sarah explained:

I grew up in Gambia. I was fortunate to be sent to school as a child. I really thank God and my parents for that because, in an area where most of the people did not value education, I was one of those lucky children who went to school. I am also fortunate that I have the opportunity to acquire further education. . . . because, back at home, the salary wasn't good enough considering the fact that I have two children to take care of. ... . in addition to other family responsibilities. I am a single parent, so, the only thing I can do is to equip myself with knowledge so that I have a better salary and a better socioeconomic position in the future.

To the question "Based on your feelings and experiences, what are the differences between life (including study) in Taiwan and life in Gambia?" they compared the reality of Taiwan to the potential of Gambia. Sarah declared:

\footnotetext{
Most importantly, I will miss the stable electricity supply, reliable Internet connection, amazing infrastructure, and excellent transportation system. I cannot remember a single instance of an electricity outage since I came. The electricity supply is 24 hours, seven days a week, and this has really made my work as a student easy. I am able to access any information online, any time of the day and night. The infrastructure refers to the basic physical and organizational structures and facilities, such as buildings and roads; they are basic and of paramount importance for the smooth operation of a society. These are fundamental necessities in any country, without which meaningful development will be difficult to attain. Equally commendable and exceptional is the transport system. Taiwan is well equipped in this area as well. I believe that a stable electricity supply, good transportation and infrastructure - education and health care systems - as well as agriculture, are keys to driving socio-economic development. I admire Taiwan for placing high priority on those areas. Thus, it is no wonder that it has become an economic growth center in the world.
}

The study participants also had concerns on how the locals stared at them. Carol had articulated it as follow: 
Whenever I got on a bus, the metro system (MRT), or stepped into any public place, some of the locals start to stare, point, and laugh at me. It is uncomfortable to be noticed in a crowd, especially because of how they persist at pointing at me and even poke others to look at me. I have observed that they don't really do that to the white people.

Besides, this study has allowed me to capture data which I would otherwise never find in literature, reviews, or documents. For example, I would never have known that some Muslims and Christians in Gambia take part in one another's activities. When I enquired about the activities they did together in communities, Sarah said: "Yeah, I attend all kinds of activities, even with Christians and Muslims. I am a Muslim, but sometimes I have Christian friends over. If they have baptism or parties, we come and celebrate it together. Normally, we do it together."

\section{Emerging Learning Experiences in Taiwan}

This study explored what the two Gambian students learned from the two main agencies of socialization: school and peer groups. The students also experienced non-formal education through self-actualization and interactions with local Taiwanese. Freire (2000a) argued that one must have epistemological curiosity to achieve unity between theory and practice. Similarly viewing the study abroad experience, the two Gambian students actualized this curiosity in their interactions with peers and local Taiwanese to learn about the culture and survive in school and society.

Freire (2000a) called this encounter or interaction between people dialogue and contended that five components make possible dialogue as conversation: love, humility, faith, hope, and critical thinking. Accordingly, Sarah's and Carol's dialogues in Taiwan were multidimensional, exposing them to a wide range of cultures, beliefs, and lifestyles. As encounters with locals, the university environment, and other foreigners enabled them to experience many cultures and move around; it was important that they had a good understanding of these realities when studying overseas. However, to get this understanding of the new reality they were living in Taiwan, these international students had to be in constant dialogue with other human beings. This was exactly what Sarah and Carol did at the university and in society, to socialize themselves and to learn and know how to set themselves up for academic success. For example, Carol explained how she was helped to settle in Taiwan to study and move around:

When we first came here, the ICDF program manager helped us to settle down and took us to the most important places and showed us how to use the bus and metro systems. My classmates have also helped me by being so friendly, and my fellow foreign students have made it easier.

Carol shared that her classmates made her learning experience easier by being open to dialogue with her as a foreigner and as a human being. She experienced and learned about the hospitability of the Taiwanese people; in her own words, "the Taiwanese are friendly, patient, and kind people."

Studying in a new land can also encounter some challenges, such as linguistic and cultural barriers, and the university system (for example, much information about the university was available only in Mandarin Chinese and thus, accessible only to local students). Unsurprisingly, both Sarah and Carol encountered difficulties while trying to dialogue with people in Taiwan. Carol shared:

The main problem I faced was trying to make people understand what I wanted to say when I went out to buy something because of the language barrier. I also found it difficult to eat with chopsticks and always had to ask for a spoon instead. Finding my way around was also a problem, which led me to getting lost a number of times. 
Sarah seemed to have similar problems as Carol, such as using chopsticks, communicating with vendors while shopping, and especially reading product labels. Sarah added that she had difficulty coping with the culture of punctuality in Taiwan. She learned that it was impolite to be tardy for school and other meetings with professors, which motivated her to change her behavior. She also mentioned particular learning problems she encountered at school:

My learning problem in the initial stage was how to manage with too many assignments and meeting deadlines for submitting assignments. But gradually, I coped with the pressure. I also had a problem understanding one of the lecturers because of his accent. He spoke too fast. But gradually, I was able to cope.

It requires humility to fit into a new culture, especially the Taiwanese culture, because everything is an object of learning. Freire (2000a) argued such humility is important to enable participating in dialogue with local people. One must keep in mind that while studying abroad, a curiosity to learn and know is important and can require individuals to make efforts to discover the world on their own. This was the case for Sarah and Carol as they accessed services by observing other people and reading instructions. They learned some things, not through any agencies, but through observations, or from their own experiences, and later seeking help from others. Among those they mentioned were how to use the school's main library, metro system, bus, and ATMs. Carol explained it was challenging when she needed to go to the library and did not know how to use the facilities:

I did not learn how to find my way around or use the materials in the university main campus library, and it was quite a challenge. When I really needed to use the library, I went with my fellow international colleagues, and we just tried to learn by trying. Later on, we got help from one of our Taiwanese classmates.

Studying in Taiwan could dramatically change international students' lifestyles, as was the case for both Sarah and Carol. For example, taking the metro, living in a dormitory, and recycling trash were not part of the lifestyle which they were used to. They needed to learn and adapt to the lifestyle in Taiwan, possible only by communicating with local Taiwanese or foreigners who already knew the system. Sarah learned how to use the metro and ATM by observing others:

I learned how to use the ATM through observation because I had never used it before. I feel it should be important to be taught to use the ATM because it took me time to understand. ... We have ATMs at home too, but I never used it, but it is something one must use in Taiwan. For the MRT, I was observant and followed what people did. And, I always have my map with me to help me locate where I want to go.

Intercultural contact remains key in this setting for any international student. Since there is a major English-speaking population in Taiwan, it will help in creating a conducive environment for studying as well as adapting to the culture. Interaction with individuals in the Taiwanese setting needs the socialization process as one adapts to the situation in the schools and the lifestyle. Most importantly, the findings have shown those students who adapt into the culture first, have excelled in making the studies become easier. However, the students have adapted to two distinct culturesthe culture of the school (i.e., adaptation of education technology and environment) and - the host culture (i.e., social adaptation) - in order to make it successfully into their studies. As part of cultural adaptation, the eating habits also need to be integrated into this process. This can definitely help the students in utilizing the locally available food.

Change of behavior for the international students remains a challenge, as the students in the foreign nation will have to adapt to new ways of doing things. Further, the findings have shown the behavior of the students had changed significantly, as they will return to their country with a different way of conduct. The change occurs continuously, as new behaviours emerge, as an 
individual unceasingly learns new things. However, during this learning process, the study shows how the social and partial inequality setting in Taiwan makes the international students suffer, unlike the native students. The social and partial inequality setting manifested in the two Gambian students' learning experiences in Taiwan (i.e., the native students were spared from the adaptation of the culture of the school, the host culture, and the local language, which was not the case for the foreign students). These psychological impacts could be a contributor to low achievement among international students.

\section{Ongoing Learning}

According to Sarah and Carol, studying abroad, especially in Taiwan, engaged them in exploring their ongoing learning processes. Once immersed in their new environment, they realized their need to better understand Taiwanese values, sensitive issues, and history. For instance, Carol stated that in her Chinese class, she learned why Taiwanese were superstitious about the number 4 after she saw it left out of a building elevator. Furthermore, she learned that certain gifts are inappropriate to offer to the Taiwanese, such as clocks and umbrellas. These gifts, along with the number 4, are symbols of death. The students needed to be aware of these cultural symbols to avoid offending local, cultural sentiments.

What fascinated me in the interviews with the two students was they were still learning, for example, how to eat with chopsticks and speak the Chinese language - all while mastering using the library system, laundry machine, and where to go shopping. For example, Sarah shared during the interview that she was cautious about how she held and placed chopsticks because her Taiwanese classmates explained the cultural beliefs about why chopsticks are put on plates in certain ways. In addition, her classmates shared with her that Taiwanese do not like to waste their food and that it is culturally valued to finish one's meals. Sarah stated she has reflected on those values and tried to follow and respect them.

According to Sarah and Carol, they learned about and became aware of cultural values after making mistakes or being motivated by curiosity to ask for explanations. For instance, curious to know why Taiwanese often ask, "Have you eaten?", they came to understand a little about the history of Taiwan and how it became a developed country today. "Ni chi le mei yo?" ("Have you eaten?") is a common, culturally significant greeting in Taiwan, showing the importance of food in everyday life. It is in fact, one of the most important values of Taiwanese society; the other one being "Hard work".

\section{Adjusting Behaviors to Better Fit Social Norms of the Host Culture}

The two students' behavior changed a lot since they moved to Taiwan. The major changes included calling people by their titles, making appointments to show respect, being punctual to avoid affronting others by being late to appointments or classes, and by not meeting deadlines. Sarah explained:

I have to check my inbox twice every day: once as soon as I wake up, and another time before going to bed. I receive all information connected to my academic work through email. This was not the practice when I was home.

Studying in Taiwan was different from studying in Gambia because most activities and information in Taiwan required new technology. Both Sarah and Carol stated it was necessary for students to possess some information technology skills (e.g., how to upload files, use Moodle, and 
surf the Internet) to survive at Taiwanese universities. To learn all these skills, they had to communicate with both Taiwanese classmates and other foreign students. Consequently, another major change was constantly communicating with others-either via emails or via small gatherings in study rooms and coffee shops. This was not the custom in Gambia, but was an integral way of doing things in Taiwan.

\title{
Sarah and Carol's Impressions of Taiwan
}

Sarah and Carol expressed interest in learning more about the culture and people of Taiwan and visiting other places around the country. Through their observations and interactions with local people, they developed their own impressions of Taiwan. This was how Sarah put it:

\begin{abstract}
I am very impressed to see how the Taiwanese are really friendly and nice with me. My professors are always concerned about my learning and understanding my life in Taiwan. They are always trying to help me, and I feel really good at my department and the campus. As a Gambian citizen with no idea about the Chinese language, customs, and traditions, I believe that my stay in Taiwan will give me a better understanding of the customs and traditions. Studying in Taiwan will not only provide me with academic experience, but it will also give me a rich and new cultural experience. I also understand that Taiwanese people don't want to hurt people. They will go the extra mile to seek help from their friends when they can't understand the language [English].
\end{abstract}

For Carol, it was not just about the local people. She also saw Taiwan as very diverse, which provided her with good learning opportunities:

Coming to Taiwan has exposed me to a wide range of cultures and lifestyles. Since so many people from different countries come to Taiwan to study or work, it has given me the opportunity to meet a lot of people and learn from them. It has also strengthened my awareness of diversity, and I have learned to appreciate it even more. This exposure has also given me the opportunity to learn Mandarin, and I have learned that the language, although complicated, can be quite interesting if paid attention to. Above all, I have seen how friendly Taiwanese are (although they may sometimes be a little bit conservative), and how beautiful the country is.

Despite all the learning experiences the students obtained while living in Taiwan, both reflected they could have learned more if they knew Chinese. They explained their knowledge was limited to greetings and basic directions. Both stated the language barrier was the main obstacle to learning more, and they had limited time to learn Chinese before coming to Taiwan.

\section{Conclusions, Implications, and Further Research}

\section{Freirean Theory on Consciousness in Taiwan and Gambia}

In experiencing a new society and reinventing Freire's (1974) methodology of teaching and learning, dialogue is the first and foremost area of consideration. As Freire (1997) suggested, "one must read the world in which words exist" (p. 211), meaning it is important to evaluate the limitations, potentials, and historical and political forces of a particular world before taking action. This can only happen through dialogue. By dialogue, Freire (2000a) referred to encounters between humans mediated by the world to name the world. Freire (2000a) proposed five characteristics essential for dialogue among humans: love, humility, faith, hope, and critical thinking. I believe true learning cannot occur for those studying abroad if they do not possess these five qualities. Learning does not happen only from reading books, although it is important to read books to understand certain aspects of the world. Without contact with local people and other foreigners, one puts oneself apart from the world and other humans. 
In these contexts, Freirean (1998) critical pedagogy can be used as a transformative or progressive pedagogy - a social and educational practice which generates new knowledge, opens up ambiguities, and challenges all hierarchical of power systems that demand veneration at the expense of dialogue and debate (Giroux, 1996). Critical pedagogy is applied to analyze the relationships among identity, culture, and differences and to examine how social bias regarding race, class, and gender can be understood from historical attributions (Giroux, 1996).

\section{Studying Abroad as Preparation for Active Global Citizenship}

One benefit of studying abroad, especially in Taiwan, is exposure to diverse lifestyles, nationalities, and cultures. Sarah explained this opportunity helped her appreciate and learn from diverse perspectives. For instance, knowing and understanding the history of Taiwan's economy inspired the international students to return and build their home countries' economies. Through class assignments, both local and foreign students learned from each other about political and economic changes. Sarah, Carol, the other international students, and local students came to reflect on related political and economic matters in their countries, indicating their desire to intervene as human beings living on one planet. Thus, these students' focus on political and economic changes on a global scale supports the global citizenship theory (Ong, 2004).

Politically speaking, Taiwan's participation in foreign aid programs translates to an act of active global citizenship. Taiwan tackles global issues such as inadequate human resources through provision of higher education scholarship to many nation-states. Although it does not mean that all Taiwanese are active global citizens, it is a catalyzer in preparing active global citizenship. More importantly, the diversity brought to Taiwan by international students has increased racial, ethnic, and even religious perspectives. Such exposure may render both local and international students, through communication and class presentation, to become aware of global issues like gender inequality, human rights, and hunger, to name a few.

\section{Education Through Travel}

Although Sarah and Carol had a positive disposition towards learning Mandarin, acquiring new technological skills, and understanding Taiwanese values to enable participating in school and society, they felt oppressed by the lack of skills (e.g., use of ATMs and language barriers) which kept them from fully participating as global citizens. Unlike the other technological skills which were transferred to them by someone, the use of ATMs was a more personal skill. Feeling oppressed in that case simply means "not being able to do things that others (i.e., the natives and long-term foreigners) are easily doing". As trivial as this can sound, the two Gambian students were hesitant to use those machines because it was never part of their daily life at home. This taught them the need for more technology skills should Gambia integrate.

Lessons for Gambia: Gambian government and its population must embrace, and if possible, implement modern infrastructure in sectors including transportation, education, technology, and trade to name a few. The implementation of such an infrastructure will better prepare their citizenry for studying abroad. The lack of such prior knowledge and experience becomes an obstacle which prevents the students from fully enjoying their new environment. This study showed Sarah and Carol struggled before they were able to adapt to the Taiwanese lifestyle. Even these inconveniences contributed to their learning experiences and raising of their consciousness. The experiences they had in Taiwan will also definitely impact their lives as Gambia improves its technology. 
Another form of oppression Sarah and Carol encountered while studying in Taiwan was being noticed in crowds, which resulted in embarrassing moments as local people persisted in pointing at them and poking others to look at them. Sarah and Carol shared that this situation encouraged Gambian students to stick together and value teamwork more. The students also learned that Taiwanese culture favors white people over black people. That said, critical travel pedagogy fits this context as it focuses on raising critical consciousness about issues of oppression and social injustices. I believe Gambia and Taiwan can better prepare their citizens to deal with this reality by providing needed information. For example, Gambians planning to travel to Taiwan can be educated beforehand about the Taiwanese people and lifestyle, and Taiwan can sensitize its population in their reactions to foreigners.

\section{Reflection as the Key to Learning Experiences}

Sarah's and Carol's many learning experiences and accomplishments in Taiwan were multidimensional. For example, they gained new academic knowledge, traveled, met other professionals (local and international), learned Chinese and other languages, and faced new challenges, proving Dewey's (1934) definition of experience: "the result, the sign, and the reward of that interaction of organism and environment which, when it is carried to the full, is a transformation of interaction into participation and communication" (p. 22). Experiential learning theory, with its two components: continuity and interaction, is also proven here because both students were aware studying abroad was an ongoing learning process. According to how these two students shared their learning experience, it is evident they used reflection, the third component of experiential learning, to enable continuing their experience. For instance, they reflected on their struggle to use modern technology in Taiwan and proposed that they should have been taught these skills.

\section{Cross-Cultural Understanding Enables Cultural Responsiveness}

Cross-cultural understanding is becoming more important as globalization eliminates borders, and higher education (or internationalization) continues to expand into new territories. Cross-cultural understanding skills can be taught not only in the classroom, but also through experience. These two Gambian students interacted with the host culture and directly observed customs (including the cultures and customs of other international students). They gained, compared, learned, and reflected on cultural attributes from every culture to which they were exposed. International students could benefit from cross-cultural diversity training to prevent mistakes and improve their cultural awareness, sensitivity, and understanding of communication style of host cultures. What may seem like a joke in one language may come across as an insult in another. Consequently, understanding cross-cultural interactions should be encouraged in everyday life while studying abroad.

\section{Consciousness Awakened: An Imperative for Women's Emancipation}

For Gambian students in Taiwan, particularly the two participants, critical pedagogy should make them think about what it means to be educated abroad - for what purpose, what kind of society, and what future. Both students shared, as Gambian women, they were fortunate to attend school. These students' views of themselves as fortunate demonstrates the oppression of women in Gambia and it has helped these students become aware of the realities of women's situation (consciousness awakening) in their communities. For example, considering their privilege of attending school, they explained that they wanted to fight discrimination against girls in Gambia. 
Sarah and Carol also observed that both Taiwanese universities consisted of men and women faculty members. Carol provided a scientific explanation (on account of the knowledge she had gained in the master's degree class on the value of national culture): "the presence of Taiwanese women professors at university is due to the fact that Taiwan is a feminine country. In contrast, women faculty members are almost non-existent in [a] Gambian university." Therefore, they stated they were hopeful of improving the situation of Gambian women if they followed in Taiwan's footsteps. Furthermore, the participants' ability to observe these cultural attributes in Taiwanese universities shows that the feminist theory, especially the feminist movement, has shown to be intimately related to action (Flax, 1983), challenging, counteracting, and changing the status quo which disadvantages and devalues women (Chafetz, 1997). Indeed, the women's rights movement has changed traditional understandings of girls and women and their aspirations in many societies today. If more women from Gambia, as well as other parts of Africa and the world, had access to education, especially higher education, women might liberate themselves from oppression.

As an additional example of contrast, Sarah and Carol observed Taiwanese professors and peers were concerned about the participants' academic progress (their satisfaction) and learning experience in Taiwan (the changes they would bring home from their experiences), proving that critical pedagogy leads to the creation of new forms of ethical and political community (Freire, 2000a). The Taiwanese professors' concerns for their students' progress could be interpreted as a way for them to evaluate the master's Program. In other words, valuable feedback from the international students will help them improve the program, and in the future, help students to achieve greater academic success and greater ease of adapting to the Taiwanese society.

Being aware of the socioeconomic, political, and sociocultural reality in Gambia, Carol said her learning experiences - that she had gained from school as well as from interacting with people of diverse nationalities whom she had encountered in Taiwan - would not only support her personal emancipation, but also contribute to the economic growth of Gambia.

\section{Final Word}

This study explored the learning experiences of two foreign students, with the aim to interpret Freire's (2000a) dialogical method as a way of learning about the world through studying abroad. First, we saw how learning helped the students socialize and integrate into school and society. Second, through the hidden curriculum and school assignments, they learned certain social values (e.g., teamwork, reciprocity, achievement, and punctuality). Third, peer groups played a critical role in their learning experiences, for example, transmitting Taiwanese culture through conversations, relationships, and the rules of interaction. The peer groups taught each other relevant social norms, skills, and values. Finally, these students used their cognitive skills to acquire knowledge about people and how to find their way around.

These were the learning experiences Sarah and Carol obtained while living in Taiwan as part of their studies. Without dialogues characterized by love, humility, faith, hope, and critical thinking, their learning experiences in Taiwan would not have been possible. They planned to attempt to change their communities in Gambia through dialogue, associated by Freire (1974) with popular or informal education (described as education for critical consciousness). Both Sarah and Carol hoped to share their learning and living experience in Taiwan through group activities in Gambia and by building new knowledge as preparation for actively working toward social change. 


\section{References}

Access Gambia. (2013a). Gambia education information. Retrieved from www.accessgambia.com/information/education.html

Access Gambia. (2013b). University of Gambia. Retrieved from www.accessgambia.com/information/university.html

Astell, M., \& Springborg, P. (2002). A serious proposal to the ladies: Parts I and II. Orchard Park, NY: Broadview.

Banks, J. A. (2008). Diversity, group identity, and citizenship education in a global age. Educational Researcher, 37(3), 129-139

Bochner, S., Furnham, A., \& Ward, C. (2001). The psychology of culture shock. East Sussex, UK: Routledge.

Burbules, N. C., \& Torres, C. A. (2000). Globalization and education: Critical perspectives. New York, NY: Routledge.

Bureau of African Affairs. (2013). U.S. Department of State. Retrieved from www.state.gov/r/pa/ei/bgn/5459.htm

Burgess, R. G. (1984). Methods of field research 2: Interviews as conversations. In R. G. Burgess (Ed.), In the field: An introduction to field research (pp. 101-122). London, UK: George Allen \& Unwin.

Burn, B. (1980). Study abroad and international exchanges. Annals of the American Academy of Political and Social Science, 449, 129-140.

Carson, T., \& Johnston, I. (2001). Cultural difference and teacher identity formation: The need for a pedagogy of compassion. Journal for the Psychoanalysis of Culture and Society, 6(2), 259-264.

Castells, M. (1997). The power of identity, the information age: Economy, society and culture (Vol. II). Cambridge, MA: Blackwell.

Chafetz, J. S. (1988). The gender division of labor and the reproduction of female disadvantage: Toward an integrated theory. Journal of Family Issues, 9(1), 108-131.

Chafetz, J. S. (1997). Feminist theory and sociology: Underutilized contributions for mainstream theory. Annual Review of Sociology, 23, 97-120.

Chomsky, N. (1998). Language and politics. New York, NY: Black Rose Books.

Chou, C. H. (2013). International students' learning experiences in Taiwanese higher education. Retrieved from https://search.proquest.com/openview/b562a2829f88a361621b307f9b50404b/1?pqorigsite $=$ gscholar\&cbl= $18750 \&$ diss $=\mathrm{y}$

Chou, C. P., Roberts, A., \& Ching, G. S. (2012). A study on the international students' perception and norms in Taiwan. Retrieved from

http://www3.nccu.edu.tw/ iaezcpc/Chinese\%20Publications_\%E7\%A0\%94\%E8\%A8\%8E\%E6\%9C\%83\% E8\%AB $\% 96 \%$ E6\%96\%87/A\%20study\%20on\%20the\%20international\%20students\%20\%20perception\%2 0and\%20norms\%20in\%20taiwan.pdf

Crone, T. S., \& Portillo, M. C. (2013). Jigsaw variations and attitudes about learning and the self in cognitive psychology. Teaching of Psychology, 40(3), 246-251.

Dewey, J. (1933). How we think: A restatement of the relation of reflective thinking to the educative process. Boston, MA: Houghton Mifflin.

Dewey, J. (1934). Art as experience. New York, NY: Minton, Balch \& Company.

Dewey, J. (1997). Experience and education (Touchstone edition). New York, NY: Simon and Schuster. (Original work published 1938)

Evans, R. J. (1977). The feminists: Women's emancipation movements in Europe, America and Australasia, 18401920. London, UK: C. Helm.

Fernandez, E. (2006). Developing a global perspective during a study-term abroad (Doctoral dissertation). Available from ProQuest Dissertations and Theses database. (UMI No. 3208455)

Flax, J. (1983). Political philosophy and the patriarchal unconscious: A psychoanalytic perspective on epistemology and metaphysics. In S. Harding \& M. Hintikka (Eds.), Discovering reality: Feminist perspectives on epistemology, metaphysics, and philosophy of science (pp. 245-281). Dordrecht, Netherlands: D. Reidel.

Freire, P. (1970). The adult literacy process as cultural action for freedom. Harvard Educational Review, 40(2), 205-225.

Freire, P. (1974). Education for critical consciousness. New York, NY: Continuum.

Freire, P. (1997). Mentoring the mentor: A critical dialogue with Paulo Freire (Vol. 60). New York, NY: Peter Lang.

Freire, P. (1998). Pedagogy of freedom: Ethics, democracy, and civic courage. Lanham, MD: Rowman \& Littlefield.

Freire, P. (2000a). Pedagogy of the oppressed (30th anniversary edition). New York, NY: Continuum.

Freire, P. (2000b). Literacy: Reading the word and the world. In A. M. A. Freire \& D. Macedo (Eds.), The Paulo Freire Reader (pp. 111-163). New York, NY: Continuum. 
Gemignani, C. L. (2009). Understanding the study abroad experience of university students (Doctoral dissertation). Retrieved from https://lib.dr.iastate.edu/etd/10624/

Giroux, H. A. (1996). Living dangerously. New York, NY: Peter Lang.

Hanvey, R. G. (1979). Cross-cultural awareness. In E. C. Smith \& L. F. Luce (Eds.), Toward internationalism: Readings in cross-cultural communication (pp. 46-56). Rowley, MA: Newbury House.

Heater, D. (2002). World citizenship: Cosmopolitan thinking and its opponents. New York, NY: Continuum.

Hobbes, T. (1998). De cive. Richard Tuck (Ed.). Cambridge, UK: Cambridge University Press. (Original work published 1642)

Jawneh, N. (2011, September 9). 25 students of urban planning class set for Taiwan. The Point. Retrieved from http://thepoint.gm/africa/gambia/article/25-students-of-urban-planning-class-set-for-taiwan

Jawneh, N. (2013, August 16). 22 Gambian students set for Taiwan studies. The Point. Retrieved from http:/thepoint.gm/africa/gambia/article/22-gambian-students-set-for-taiwan-studies

Johnstone, B. (2011, May). Action research and the development of critical travel pedagogy. Paper presented at the annual meeting of the 55th Annual Conference of the Comparative and International Education Society, Fairmont Le Reine Elizabeth, Montreal, Quebec, Canada.

Johnstone, B. (2014). Critical travel pedagogy: Promoting a critical consciousness through international travel experiences (Doctoral dissertation, University of California). Retrieved from https://cloudfront.escholarship.org/dist/prd/content/qt7qs7s4f9/qt7qs7s4f9.pdf

Jonasdottir, A. G. (1994). Why women are oppressed. Philadelphia, PA: Temple University.

Kauffman, N., Martin, J., Weaver, H., \& Weaver, J. (1992). Students abroad: Strangers at home. Yarmouth, ME: Intercultural Press.

Killick, D. (2016). The role of the hidden curriculum: institutional messages of inclusivity. Journal of Perspectives in Applied Academic Practice, 4(2), 20-24.

Kumashiro, K. (2000). Teaching and learning through desire, crisis, and difference: Perverted reflections on antioppressive education. The Radical Teacher 58, 6-11.

Lemak, J. A., \& Hopkins-Benton, A. (2017). Votes for women: Celebrating New York's suffrage centennial. New York, NY: SUNY.

Lindsey, L. L. (2015). Gender roles: A sociological perspective. New York, NY: Routledge.

Mansilla, V. B., \& Gardner, H. (2007). From teaching globalization to nurturing global consciousness. In S. Orozco (Ed.), Learning in the global era: International perspectives on globalization and education (pp. 47-66). Berkeley, CA: University of California.

Marshall, C., \& Rossman, G. B. (2006). Data collection methods. In C. Marshall \& G. B. Rossman (Eds.), Designing qualitative research (4th ed.; pp. 97-150). Thousand Oaks, CA: Sage Publication.

Ministry of Foreign Affairs, Republic of China, Taiwan. (2012). International cooperation and development report 2010. Retrieved from https://www.mofa.gov.tw/Upload/RelFile/17/262/fe7c546c-1159-4867ae80e5eec9f8b625.pdf

Nieto, S. (2004). Critical multicultural education and students' perspectives. In G. Ladson-Billings \& D. Gillborn (Eds.), The Routledge Falmer reader in multicultural education (pp. 179-200). London, UK: Routledge Falmer.

Nkwi, P. N., Nyamongo, I. K., \& Ryan, G. W. (2001). Field research into socio-cultural issues: Methodological guidelines. Yaoundé, Cameroon: International Center for Applied Social Sciences, Research, and Training.

Offen, K. (1988). Defining feminism: A comparative historical approach. Signs: Journal of Women in Culture and Society, 14(1), 119-167.

Okin, S. M. (1979). Women in western political thought. Princeton, NJ: Princeton University.

Ong, A. (1999). Flexible citizenships: The cultural logics of transnationality. Durham, NC: Duke University.

Ong, A. (2004). Higher learning: Educational availability and flexible citizenship in global space. In J. A. Banks (Ed.), Diversity and citizenship education: Global perspectives (pp. 49-70). San Francisco, CA: JosseyBass.

Ostrand, K. D. (1986). Trips and tours: Combining theory and reality through educational travel. New Directions for Continuing Education, 30, 83-89.

Owen, D. (1999). Hume's reason. Oxford, UK: Oxford University.

Peters, M. A., Blee, H., \& Britton, A. (2008). Many faces of global civil society: Possible futures for global citizenship. In M. A. Peters, A. Britton, \& H. Blee (Eds.), Global citizenship education: Philosophy, theory and pedagogy (pp. 1-13). Rotterdam, Netherlands: Sense.

Republic of Gambia. (2015). Education for all 2015 national review report: Gambia. Retrieved from http://unesdoc.unesco.org/images/0023/002314/231425e.pdf 
Rodriguez, K. (2014). The perceived impact of study abroad activities for graduate counseling students (Doctoral dissertation, Texas A\&M University-Corpus Christi). Retrieved from https://tamuccir.tdl.org/handle/1969.6/574

Springborg, P. (2005). Mary Astell: Theorist of freedom from domination. Cambridge, UK: Cambridge University.

Steves, R. (2012, January 18). Study abroad is necessity, not luxury. USA Today. Retrieved from http://usatoday30.usatoday.com/news/opinion/forum/story/2012-01-18/study-abroad-global-economytravel $/ 52650834 / 1$

Stiglitz, J. E. (2002). Globalization and its discontents. New York, NY: Norton.

Study Abroad (n.d.). The world is your classroom. Retrieved from https://www.unomaha.edu/college-of-arts-andsciences/mathematics/student-opportunities/study-abroad.php

Szelenyi, K., \& Rhoads, R. A. (2007). Citizenship in a global context: The perspectives of international graduate students in the United States. Comparative Education Review, 51(1), 25-47.

Touraine, A. (1988). Return of the actor: Social theory in postindustrial society. Minneapolis, MN: University of Minnesota.

Touray, I. (2006). Sexuality and women's sexual rights in Gambia. IDS Bulletin, 37(5). Retrieved from http://www.b-fair.net/wp-content/uploads/2010/12/DOWNLOAD-THE-ARTICLE.pdf

Vallance E. (1974). Hiding the hidden curriculum: An interpretation of the language of justification in the nineteenth-century educational reform. Curriculum Theory Network, 4(1), 5-22.

Vijeyavelan, K. (2012). How important is socializing while studying abroad? Retrieved from http://www.uniguru.co.in/blog/how-important-is-socializing-while-studying-abroad/16932/

Walby, S. (1986). Patriarchy at work. Cambridge, UK: Polity.

Walby, S. (1990). Theorizing patriarchy. Oxford, UK: Blackwell.

Wollstonecraft, M. (1988). A vindication of the rights of women. In C. H. Poston (Ed.), A vindication of the rights of women $\left(2^{\text {nd }}\right.$ ed.). New York, NY: W. W. Norton. (Original work published 1792)

Wyrod, R. (2008). Between women's rights and men's authority: Masculinity and shifting discourses of gender difference in urban Uganda. Gender \& Society, 22(6), 799-823.

Yang, C., \& Chang, Y. S. (2012). Assessing the effects of interactive blogging on student attitudes towards peer interaction, learning motivation, and academic achievements. Journal of Computer Assisted Learning, 28(2), 126-135.

\section{Acknowledgement}

The author would like to show special appreciations to her adviser, Professor Hsiao-Lan Sharon Chen. 